\title{
Distribution and adaptive strategies of alcyonacean corals in Nanwan Bay, Taiwan
}

\author{
Chang-Feng Dai \\ Institute of Oceanography, National Taiwan University, PO Box 23-13, Taipei, Taiwan
}

Key words: alcyonaceans, distribution pattern, adaptive strategy

\begin{abstract}
The factors responsible for the abundance and distribution patterns of alcyonacean corals on the fringing reefs in southern Taiwan have been investigated. Transplantation studies have shown that the lack of alcyonacean corals in current- and storm-protected areas is possibly due to smothering by heavy sedimentation and with interactions with the alga Codium sp. Studies on the changes of alcyonaceandominated communities revealed that alcyonacean corals are susceptible to storms but colonies often suffer only partial damage, even in severe storms. The remnants of these colonies can undergo rapid regeneration after storms which enables them to occupy space effectively, and may account for their dominance in storm-swept reefs.
\end{abstract}

\section{Introduction}

Alcyonacean corals are one of the major sessile invertebrates on Indo-Pacific reefs (Cary, 1931; Crossland, 1938) and often monopolize local space wherever they are present (Benayahu \& Loya, 1977; Tursch \& Tursch, 1982; Dai, 1988). However, the relationships between environmental factors and their distribution patterns are still poorly known.

There is a significant difference in the coral fauna between the east and the west sides of Nanwan Bay, Taiwan (Dai, 1988). Coral communities on the west side of the bay are dominated by alcyonacean corals, which comprise $\mathrm{ca} 75 \%$ of the total coral cover, while on the east side of the bay, scleractinian corals comprise $>95 \%$ of the total coral cover.

There are at least two possible explanations for the rarity of alcyonacean corals on the east side of the bay. Firstly, there may be a dispersal barrier that prevents alcyonacean larvae from reaching the east side and secondly, physical and biological factors may restrict alcyonacean abundance. Since the current pattern of the bay shows a considerable mixing of water masses during successive tidal cycles (Liang et al., 1978) and small alcyonacean colonies do exist on the east side of the Bay, there appear to be no barriers to larval dispersal. A transplantation study was conducted to investigate the possible mechanisms that lead to the observed faunal differences.

With regard to the question of why alcyonaceans are abundant on the west side of the bay, two factors were considered. Firstly, the competitive abilities of both alcyonacean and scleractinian corals (Dai, 1990), since alcyonacean corals may be dominant in competition with scleractinian corals (Benayahu \& Loya, 1977; Sammarco et al., 1983, 1985) and may become dominant in the community. Secondly, alcyonacean corals may have other adaptive strategies which enable them to dominate the coral communities. To investigate this, the 
changes in an alcyonacean-dominated community over 2 y were monitored.

\section{Material and methods}

The study site

Field observations and experiments were made on the fringing reefs of Nanwan Bay in southern Taiwan $\left(21^{\circ} 55^{\prime} \mathrm{N}, 120^{\circ} 45^{\prime} \mathrm{E}\right)$. Previous studies in the bay have recorded 218 species of scleractinian corals and 36 species of alcyonacean corals (Dai, 1988). The marine fauna of the study area is strongly influenced by the warm Kuroshio Current, and has a strong affinity with those of the Philippines and the Ryukyu Islands. Studies on the environmental factors of Nanwan Bay have shown that the east side of the Bay is protected from tidal currents and storm surges, while the west side is exposed to both (Liang et al., 1978; Hung et al., 1984).

\section{Transplantation}

Forty-four alcyonacean colonies from the west side of the bay were transplanted to the east side. These were 10 colonies of Sarcophyton trocheliophorum, 10 of Sarcophyton crassocaule, 10 of Lobophytum sarcophytoides, 4 of Lobophytum solidum, 4 of Sinularia grandilobata, 3 of Sinularia polydactyla and 3 of Sinularia numerosa. The colonies, ranging from 11 to $15 \mathrm{~cm}$ diam., were detached with a chisel and a hammer, immersed in a seawater tank and transported immediately to the east side. The soft coral was fastened with sewing thread around its base to a plastic pot filled with coral débris. The pots were wired to a frame and fixed to the reef bottom at $10 \mathrm{~m}$. The same numbers of colonies were treated in the same way and transplanted on the west side to serve as a control group. The transplantations were conducted on 12-13 February 1987. Observations and measurements of transplanted colonies were conducted after $2 \mathrm{~d}, 4 \mathrm{~d}, 1$ week, 2 weeks, 1 month, and every month thereafter for 7 months. The diameters of each colony in two perpendicular dimensions $\left(\mathrm{d}_{1}, \mathrm{~d}_{2}\right)$ were measured with calipers to calculate the capitulum area.

\section{Changes in coral communities}

Three plots $(1 \times 5 \mathrm{~m}$ each $)$ on the west side of the bay were established parallel with the $8 \mathrm{~m}$ depth contour. Each plot was marked with nails and wire and divided into 5 consecutive $1 \mathrm{~m}^{2}$ quadrats.

The plots were photographed using a Nikonos $\mathrm{V}$ camera $(20 \mathrm{~mm}$ lens, Kodachrome 100 slide film) with an underwater strobe (SB 102). Each $1 \mathrm{~m}^{2}$ quadrat was centered in the viewfinder and photographed from a perpendicular distance of about $1.8 \mathrm{~m}$, giving minimal lateral distortion and sufficient depth of field. The small effects of variation in camera position were overcome by use of a series of in situ reference points and by in situ measurements.

Coral colonies in the plots were measured in situ by using a $1 \mathrm{~m}$ square stainless steel frame divided by wires into $100 \mathrm{~cm}^{2}$ areas. The distribution of coral colonies was mapped on a plastic plate, and the size of each coral colony was measured by counting the grids it occupied. The drawings and measurements of colonies in a plot provide a basis for calibrating the distortion of photographs as well as the lateral growth rate of coral colonies.

Each photograph was projected onto white paper and the outline of each component was traced. The substrate was classified into 6 categories: stony corals, soft corals, algae, bare rock, sediment, and 'others'. The surface areas of each component and each colony on the maps were measured using a digitizer and microcomputer (Eyecom II and PDP-11).

\section{Results}

\section{Transplantation}

The changes in colony area for the two groups of transplanted alcyonaceans (experimental and 
control) are shown in Fig. 1. Since no significant differences among species were detectable, data for all colonies at a site were combined. Experimental colonies decreased in colony area. Severe decreases were found in April, May and August, 1987. Field observations indicated that the decreases in April and May were caused by the green alga, Codium sp. Blooms of Codium sp. began in late March and ended in early May. During this period, they formed huge, thick, interwoven mats which extensively covered the reef surfaces. Severe tissue necrosis of alcyonacean corals was found on the edge in contact with, or adjacent to, the Codium mat; indicating that the alga may release allelochemicals which affect the alcyonaceans. The decrease of colony area in August was probably caused by the accumulation of sediment on the surface of colonies. Tissue disintegration occurred on surfaces with heavy accumulations. Most of the colonies were pale and contracted in August 1987. Colonies of the control group showed consistent increases in area
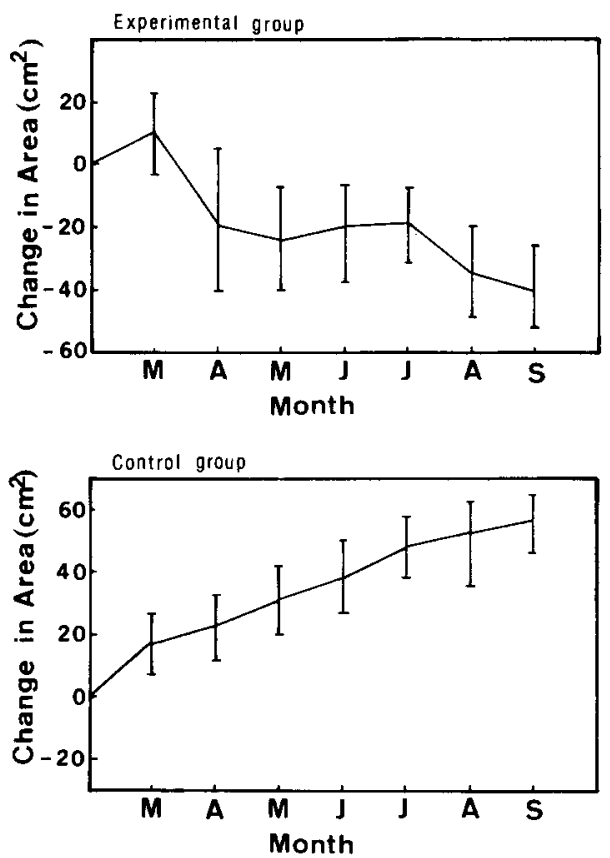

Fig. 1. Changes of capitulum area of alcyonacean corals for experimental and control groups. The original capitulum areas (in February 1987) were from 98 to $176 \mathrm{~cm}$ for the experimental groups and from 95 to $167 \mathrm{~cm}$ for the control group. Bars indicate ranges. during the study period. A Codium bloom did not occur, and sediment accumulation was negligible at the control station. This difference is possibly due to the greater water movement on the west side of the bay.

\section{Changes in coral communities}

The changes in space partitioning pattern of the 3 plots are shown in Fig. 2. The large changes in coral cover between July and October 1987 were caused by 2 successive strong typhoons which caused substantial damage to the reefs, greatly reducing the substrate covered by corals and creating large areas of bare surfaces. Both alcyonaceans and scleractinians were heavily damaged by the storms, but alcyonaceans recovered more rapidly than scleractinians because of their faster growth rate.

$\mathrm{Ca} 87 \%$ and $83 \%$ of coral colonies in Plots II and III respectively were destroyed during the storm. These were mainly Sinularia granosa and Nephthea erecta but subsequently, colonies of these species rapidly increased coverage by asexual budding. This implies that they are probably opportunist species. Other common alcyonaceans such as Sarcophyton crassocaule, Lobophytum sarcophytoides and Sinularia polydactyla showed a substantial reduction in cover but very little change in number of colonies. This is because colonies of these species often suffered partial damage but rarely whole colony mortality even in severe storms. Hence they are probably tolerant species.

\section{Mortality of coral colonies}

Mortality of corals caused by typhoons was often related to colony size. Most small colonies of Sarcophyton, Lobophytum and Sinularia suffered whole colony mortality while most large colonies were only partially injured to varied extents (Fig. 3). There appeared to be a size refuge for whole-colony mortality of alcyonacean corals; colonies larger than $500 \mathrm{~cm}$ survived even in the most heavily damaged areas. 

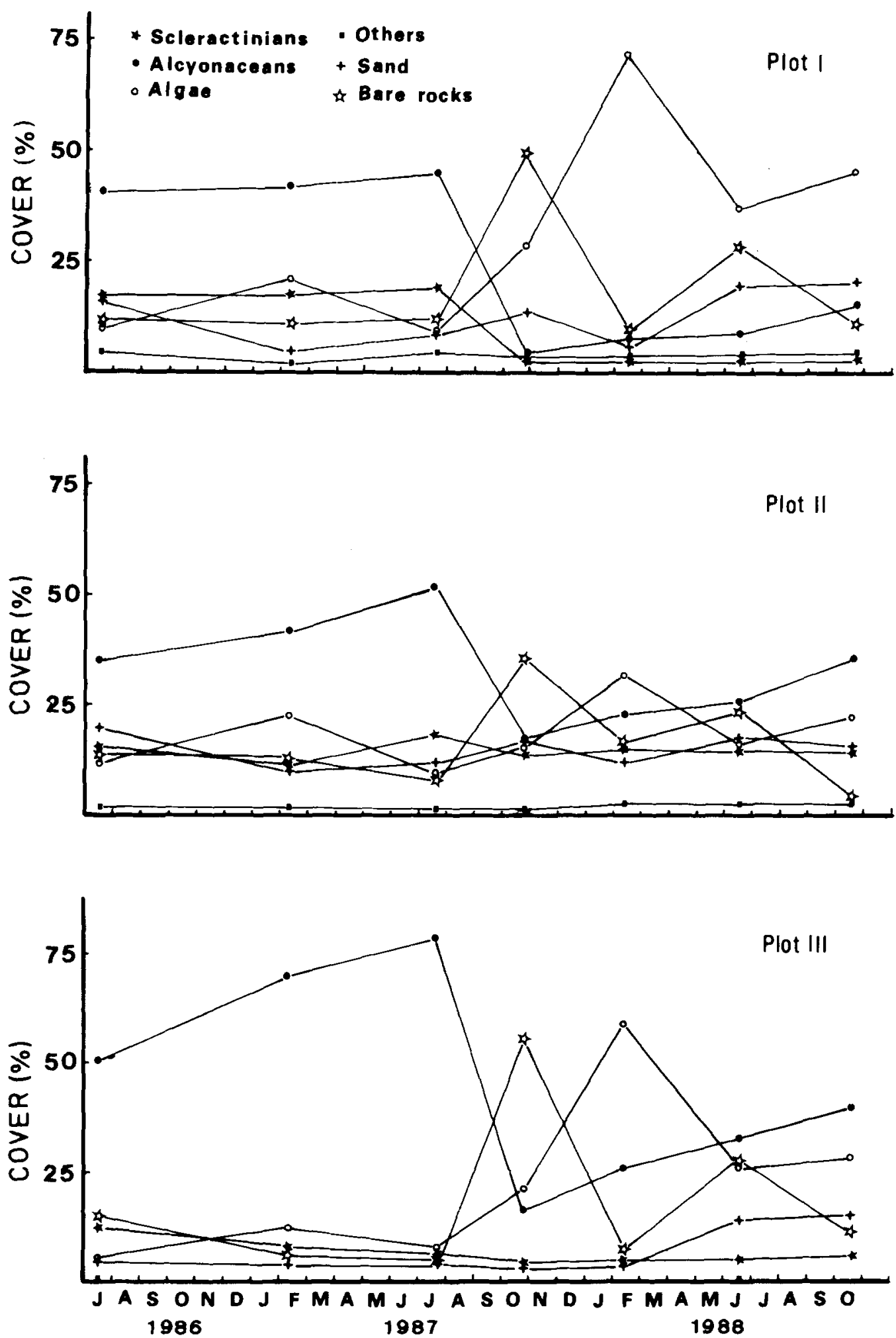

Fig. 2. Changes in space partitioning pattern of the 3 plots in Nanwan Bay from July 1986 to June 1988. 


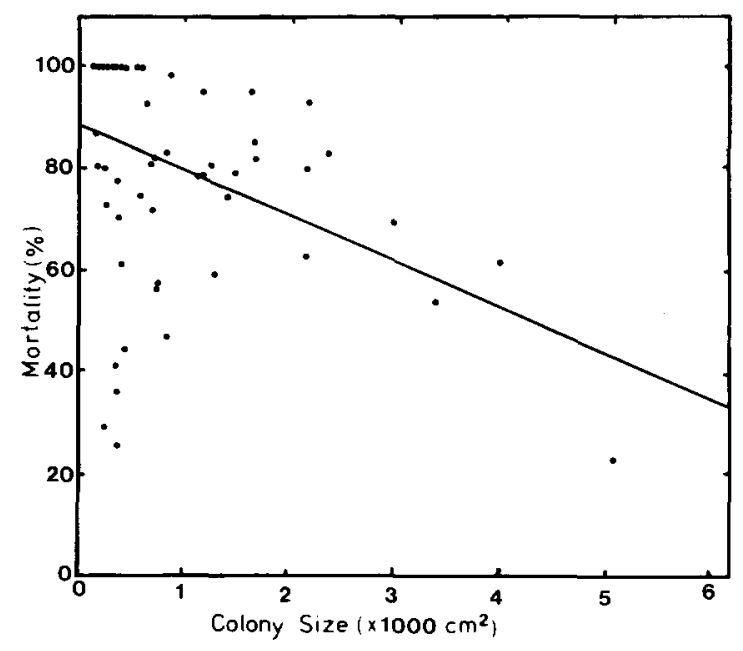

Fig. 3. Mortality ( $\%$ tissue loss) and colony size of alcyonacean corals in the 3 plots during the typhoons in September-October 1987. $r=-0.392, n=62, P<0.01$.

\section{Discussion}

The results of the transplantation study indicate that the lack of alcyonacean corals on the east side of Nanwan Bay is possibly due to environmental factors. Smothering by heavy sedimentation and lethal effects of Codium sp. may be the primary factors that restrict the abundance of alcyonaceans. Both of these phenomena are related to the relatively low water movement at the east side of the bay.

Dinesen (1983) found that alcyonacean corals, especially Alcyoniidae and Nephtheidae, apparently favor growing on outer and mid-shelf slopes where the water clarity and circulation is high. Since in alcyonacean corals the living tissues are spread throughout the bulk of the colony, as the colony grows larger, stronger water flow will be required to bring in essential substances and carry away wastes (Tursch \& Tursch, 1982). In addition, in calm waters sediment accumulation is heavier, which is harmful to alcyonacean corals.

Since alcyonaceans possess neither effective nematocysts capable of defense against neighboring organisms nor mesenterial filaments capable of extracoelenteric digestion, they are subordinate in terms of aggressiveness (Dai, 1990). However, alcyonaceans may employ alter- native strategies which enable them to be significant space occupants on Indo-Pacific reefs.

Studies on the changes of alcyonaceandominated communities revealed that alcyonacean species may be either opportunist or tolerant species. Stephenson et al. (1958) found that soft corals which suffered the least cyclone damage spread rapidly following a storm and competed with hard corals for the available substrate. The spicule-reinforced tissue and flexibility of soft corals (Koehl, 1982) enables them to survice storm disturbances. Although soft corals can usually survive minor or intermediate storms, they are susceptible to severe storms. However, large colonies only suffer partial mortality by storms and the remnants of the colonies can undergo fast recovery and regeneration that enables them to recapture space effectively. Different species of soft corals also react differently to storm disturbances: such differences reflect variations in life history characteristics (Jackson \& Hughes, 1985). Thus, Nephthea erecta and Sinularia granosa, which suffer high whole-colony mortality by storms but can undergo rapid colony division and growth, have opportunistic characteristics while Sarcophyton crassocaule, Lobophytum sarcophytoides and Sinularia polydactyla, colonies of which often suffer only partial damage, are tolerant species. These adaptive strategies of alcyonacean corals may account for their abundance on storm-swept reefs.

\section{Acknowledgements}

I thank Mr Y. C. Tsay for his assistance with field work. I am grateful to Dr R. G. Hughes and two anonymous reviewers for their critical reading. This study was supported by National Science Council, R.O.C. (NSC-78-0421-B-003-01z).

\section{References}

Benayahu, Y. \& Y. Loya, 1977. Space partitioning by stony corals, soft corals and benthic algae on the coral reef of the northern Gulf of Eilat (Red Sea). Helgoländer wiss. Meeresunters. 30: 362-382. 
Cary, L. R., 1931. Studies on the coral reefs of Tutuila, American Samoa with special reference to the Alcyonaria. Pap. Dep. mar. Biol. Carnegie Instn. Wash. 27: 53-98.

Crossland, C., 1938. The coral reefs at Ghardaqa, Red Sea. Proc. zool. Soc. Lond. (Ser. A) 108: 513-523.

Dai, C.-F., 1988. Coral communities of southern Taiwan. Proc. 6th int. Coral Reef Symp. 2: 647-652.

Dai, C.-F., 1990. Interspecific competition in Taiwanese corals with special reference to interactions between alcyonaceans and scleractinians. Mar. Ecol. Prog. Ser. 60: 291-297.

Dinesen, Z. D., 1983. Patterns in the distribution of soft corals across the central Great Barrier Reef. Coral Reefs 1: 229-236.

Hung, T. C., C. C. Su, Y. M. Chiang, T. H. Tan, K. H. Chang, R. T. Yang, Y. M. Cheng, K. L. Fan \& H. T. Chang, 1984. An ecological survey on the waters adjacent to the nuclear power plant in southern Taiwan. Nat. Sci. Comm. Prob. Environ., Spec. Publ. No. 27, 214 pp.

Jackson, J. B. C. \& T. Hughes, 1985. Adaptive strategies of coral reef invertebrates. Am. Scient. 73: 265-274.
Koehl, M. A. R., 1982. Mechanical design of spicule-reinforced connective tissues: stiffness. J. exp. Biol. 98: 239-267.

Liang, N. K., S. L. Lien, W. C. Cheng \& H. T. Chang, 1978. Oceanographic investigation in the vicinity of Ma-anshan-Nan-wan Bay. Inst. Oceanogr., Natn. Taiwan Univ. Spec. Publ. 18, 207 pp.

Sammarco, P. W., J. C. Coll \& S. La Barre, 1985. Competitive strategies of soft corals (Coelenterata: Octocorallia). II. Variable defensive responses and susceptibility to scleractinian corals. J. exp. mar. Biol. Ecol. 91: 199-215.

Sammarco, P. W., J. C. Coll, S. La Barre \& B. Willis, 1983. Competitive strategies of soft corals (Coelenterata: Octocorallia): allelopathic effects on selected scleractinian corals. Coral Reefs 1: 173-178.

Stephenson, W., R. Endean \& I. Bennett, 1958. An ecological survey of the marine fauna of Low Isles, Queensland. Aust. J. mar. Freshwat. Res. 9: 261-318.

Tursch, B. \& A. Tursch, 1982. The soft coral community on a sheltered reef quadrat at Laing Island (Papua New Guinea). Mar. Biol. 68: 321-332. 